\title{
Abstract
}

\section{The Molecular Analysis of BRCA1 Mutations in the First Slovak Patients with Suspected Familial Breast Cancer}

L. Kulcsar ${ }^{1}$, V. Bella ${ }^{1}$, M. Reinerova ${ }^{2}$, Z. Veselovska ${ }^{2}$ and V. Zajac ${ }^{2}$

${ }^{1}$ National Cancer Institute, Klenova 1, 83301 Bratislava, Slovakia

${ }^{2}$ Cancer Research Institute, Slovak Academy of Sciences, Vlarska 7, 83391 Bratislava, Slovakia

The analysis of BRCA1 mutations of 20 Slovak patients with suspected hereditary breast cancer was performed. Since more than $75 \%$ of
BRCA1 gene alterations result in a truncated protein, due to nonsense or frameshift mutations, the protein truncation test (PTT) has been used. Exons $2-10$ and $12-24$ were screened by PTT after RT-PCR using lymphocyte RNA. The largest exon 11 was divided into three parts by primers and the protein products were obtained using the TNT T7 coupled reticulocyte system. Truncated proteins were detected in material from two patients. To confirm PTT results, SSCP technique has been used for analysis of exons 2, 3, 5, 18, 20, 21 and 22. 


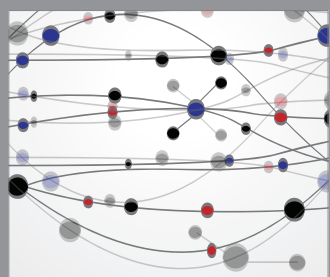

The Scientific World Journal
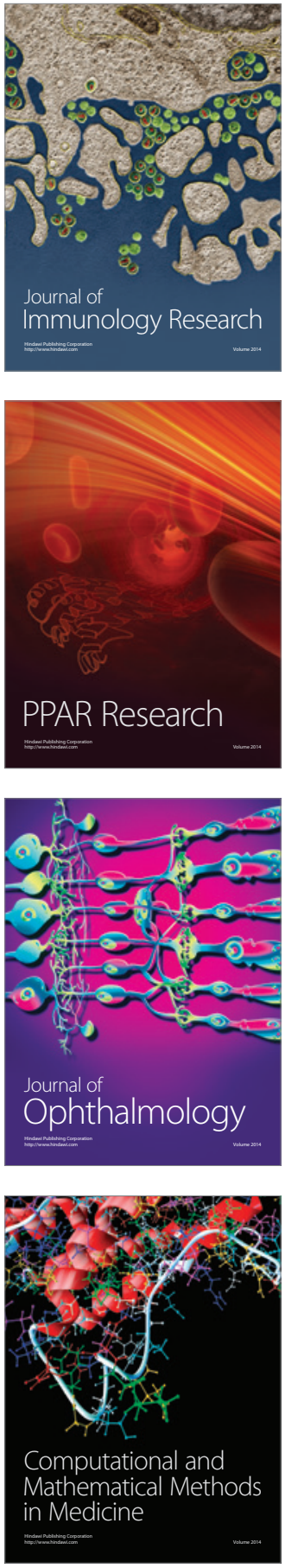

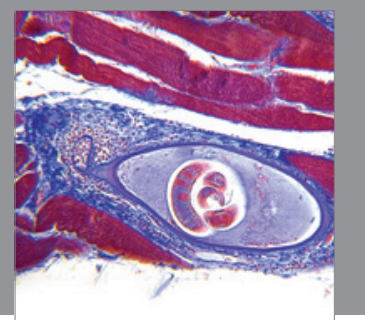

Gastroenterology

Research and Practice
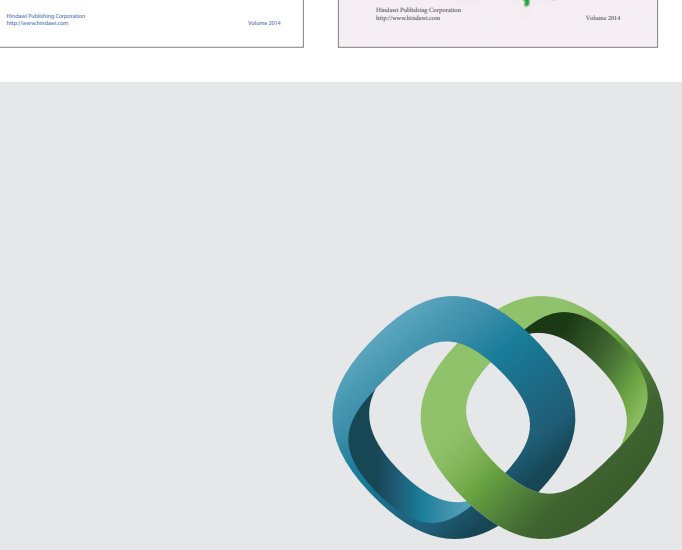

\section{Hindawi}

Submit your manuscripts at

http://www.hindawi.com
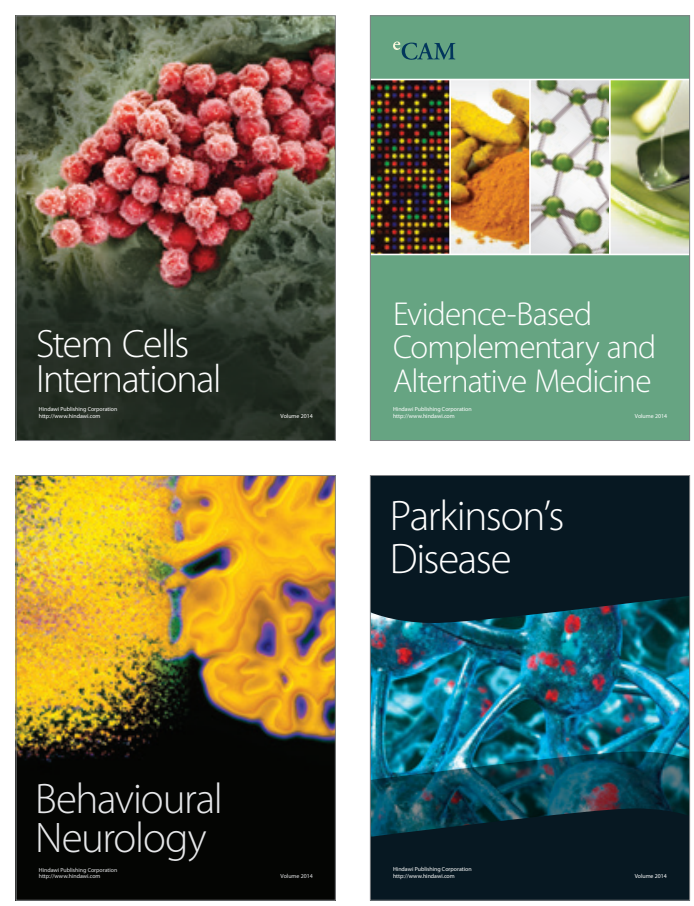

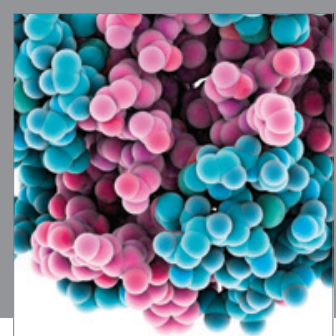

Journal of
Diabetes Research

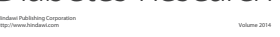

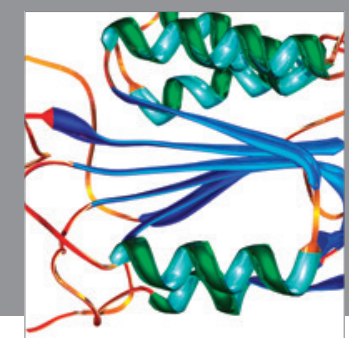

Disease Markers
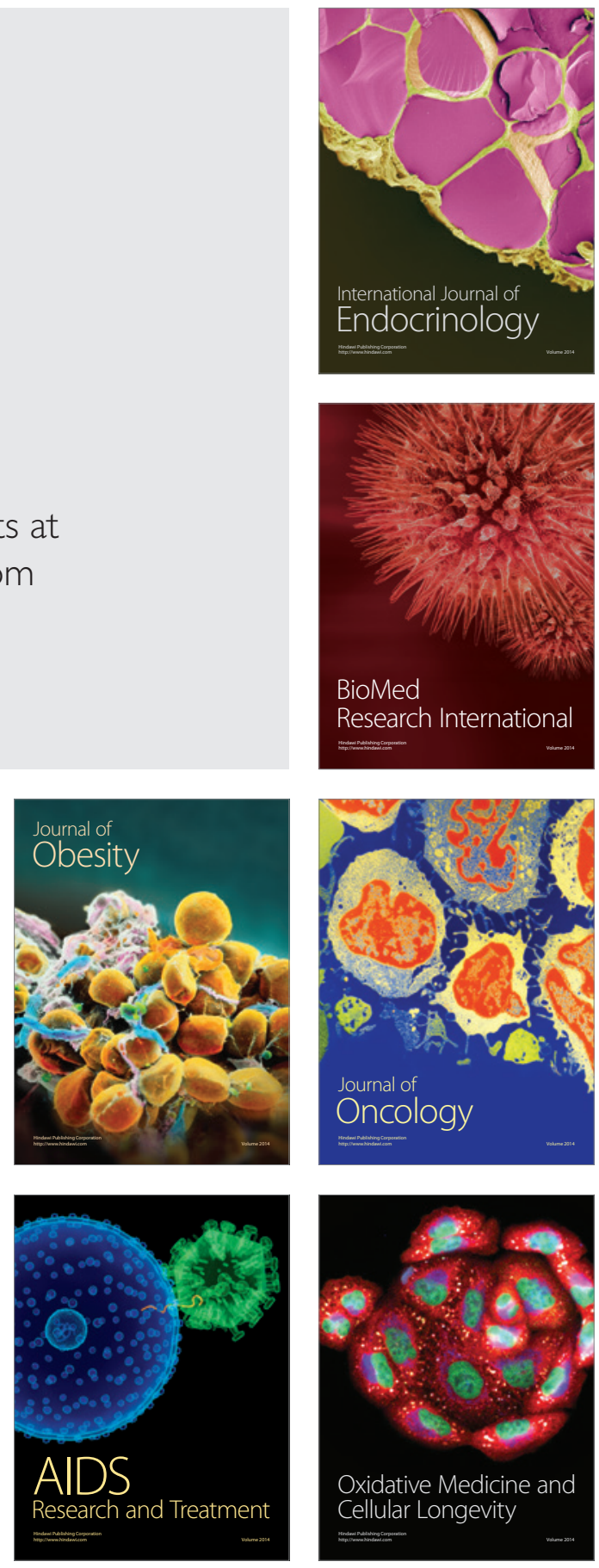